\title{
REGRESSION METHODS TO INVESTIGATE THE RELATIONSHIP BETWEEN FACIAL MEASUREMENTS AND WIDTHS OF THE MAXILLARY ANTERIOR TEETH
}

\author{
Type: Article
}

\section{Abstract:}

Statement of problem. In rehabilitating edentulous patients, selecting appropriately sized teeth in the absence of preextraction records is problematic. Purpose. The purpose of this study was to investigate the relationships between some facial dimensions and widths of the maxillary anterior teeth to potentially provide a guide for tooth selection Material and methods. Sixty full dentate Malaysian adults (18-36 years) representing 2 ethnic groups (Malay and Chinese), with well aligned maxillary anterior teeth and minimal attrition, participated in this study Standardized digital images of the face, viewed frontally, were recorded Using image analyzing software, the images were used to determine the interpupillary distance (IPD), inner canthal distance (ICD), and interalar width (IA) Widths of the 6 maxillary anterior teeth were measured directly from casts of the subjects using digital calipers Regression analyses were conducted to measure the strength of the associations between the variables (alpha=10) Results. The means (standard deviations) of IPD, IA, and ICD of the subjects were 62.28 (2.47), 39 36 (3 12), and 34.36 (2 15) $\mathrm{mm}$, respectively The mesiodistal diameters of the maxillary central incisors, lateral incisors, and canines were 8.54 (0 50), 709 (0.48), and 7.94 (0 40) $\mathrm{mm}$, respectively. The width of the central incisors was highly correlated to the IPD $(r=0.99)$, while the widths of the lateral incisors and canines were highly correlated to a combination of IPD and IA ( $r=099$ and 0.94 , respectively) Conclusions. Using regression methods, the widths of the anterior teeth within the population tested may be predicted by a combination of the facial dimensions studied (J Prosthet Dent 2010, 103 182-188)

\begin{tabular}{|c|c|}
\hline Author & $\begin{array}{ll}\text { - } & \text { Isa, Z. M. } \\
\text { - } & \text { Tawfiq, O. F. } \\
\text { - } & \text { Noor, N. M. } \\
\text { - } & \text { Shamsudheen, M. I. } \\
\text { - } & \text { Rijal, O. M. }\end{array}$ \\
\hline Source & Journal of Prosthetic Dentistry \\
\hline ISSN & $0022-3913$ \\
\hline DOI & $10.1016 / \mathrm{s} 0022-3913(10) 60028-5$ \\
\hline Volume (Issue) & 103(3) \\
\hline Page & $182-188$ \\
\hline Year & 2010 \\
\hline
\end{tabular}

Keyword:

racial groups, selection, tooth, guide, arch 
Please Cite As:

ISA, Z. M., TAWFIQ, O. F., NOOR, N. M., SHAMSUDHEEN, M. I. \& RIJAL, O. M. 2010. REGRESSION METHODS TO INVESTIGATE THE RELATIONSHIP BETWEEN FACIAL MEASUREMENTS AND WIDTHS OF THE MAXILLARY ANTERIOR TEETH. Journal of Prosthetic Dentistry, 103, 182-188.

URL:

- http://apps.webofknowledge.com search via Accession No >> 000277870000007

- http://www.scopus.com/inward/record.url?eid=2-s2.077149154972\&partnerID=40\&md5=10a15e7ba0aaabeb7038bd6ffee627d6

- http://www.sciencedirect.com/science/article/pii/S0022391310600285 